\title{
Investigation on External Explosions during Venting
}

\author{
BAOCHUN FAN, XIAOHAI JIANG, ZHIHUA CHEN, JINGFANG YE, and \\ GANG DONG \\ National Key Laboratory of Transient Physics \\ Nanjing University of Science and Technology \\ 200 Xiaolingwei \\ Nanjing 210094, China
}

\begin{abstract}
The external explosions may occur in an explosion venting and give a potential risk. However, the basic dynamic process of external explosions during the venting to ambient air is yet not well understood. In this paper, a series of vented explosion tests in high failure pressure has been conducted in a cylindrical venting vessel. It has been demonstrated clearly from the pressure-time histories and the shadowgraphs of the external flow field that under some suitable venting conditions there exist two peak pressures in the external flow field, one is generated from the membrane rupture and the other is induced by the external explosion due to the violent combustion of the vented combustible gas. The effects on the flow patterns outside the venting vessel under different failure pressures, vent areas (blockage ratio) and chemical equivalent ratios are also discussed in the term of the experimental results. Moreover, the venting process was simulated numerically by using SIMPLE schemes in colocated grid, based on the $k-\varepsilon$ turbulent model and 'eddy dissipation combustion model'. The calculated results are in good agreement with the measured results. The dominant mechanisms of the occurrence of the external explosion during the venting processes have been elucidated based on measured and calculated results.
\end{abstract}

KEYWORDS: gas explosion, venting, external explosion

\section{INTRODUCTION}

Explosion venting is one of the protective techniques applied widely in industry, by discharging the high pressure burned and unburned gas to the external air for avoiding internal explosions. However, under some suitable venting conditions, the overpressures in the external flow field might rise rapidly and become strong enough to give a potential risk to the ambient equipments, workmen and so on, called the external explosion. Therefore, investigations on the external explosion occurring in venting are of practical importance for the optimal design of venting arrangements to avoid loss and constitute the reasonable safety regulations.

Many experimental and theoretical investigations on the internal flow field in the venting devices have been performed in recent years[1-5], including the mechanics of internal overpressures, the establishment or validation of empirical equations, the ascertainment of the best vent area to design the practical venting devices and so on.

However, studies on the external flow field in the venting are fewer than the ones on the internal flow field [6-8]. Based on the spherical and ellipsoidal blast wave theory, Tom Forceier et al. [6] provided a correlation to calculate the external overpressure in venting. Harrison et al. [7] discussed the influence of external explosions on internal pressure under the different experimental conditions in a $30 \mathrm{~m}^{3}$ explosion chamber. Catlin [8] 
discussed the external jet explosions caused when a confined explosion vents gas into a combustible cloud existed already before venting.

The basic understanding of dominant mechanisms and dynamic processes of the formation and evolution of external explosions during the venting in ambient air is still unsatisfactory. In present paper, a series of venting tests was implemented in a cylindrical venting vessel by venting the high pressure burned and unburned gas into ambient air. The shadow photographs and the pressure-time profiles at several locations in the external flow fields were acquired to clarify the occurrence of the external explosion and to discuss effects of varying factors on the external explosions. Numerical simulations of the venting explosion were performed by using SIMPLE schemes in colocated grids based on the $k-\varepsilon$ turbulent model and 'eddy dissipation combustion model'. The tendencies shown by calculated and measured results were found to be in good agreement. The processes of formation and evolution of external explosions observed from both the experiments and the numerical simulations are presented and discussed.

\section{EXPERIMENTAL}

The experiments were carried out in a steel cylindrical vessel with $300 \mathrm{~mm}$ long and 180 mm inner diameter, which is shown schematically in Fig. 1.

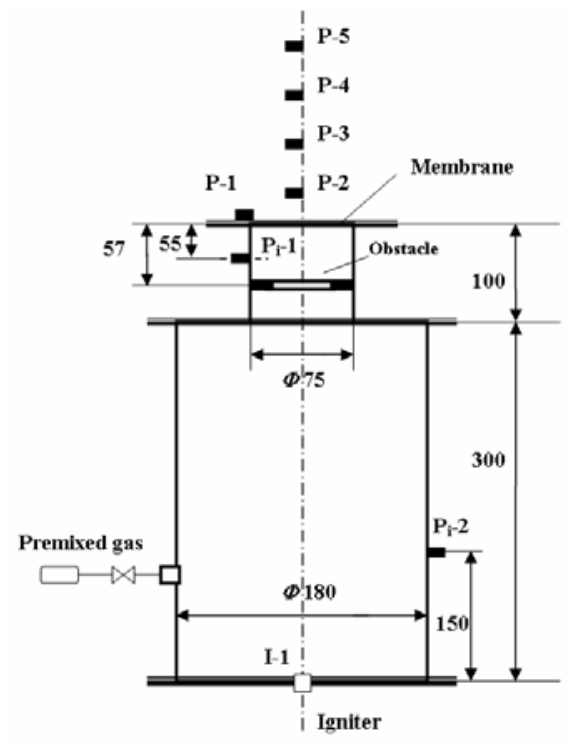

Fig. 1. Schematic diagram of a vent vessel.

The rear end of the vessel was sealed with a flange mounted with a spark igniter. The other end of the vessel was connected with a venting duct with $75 \mathrm{~mm}$ inner diameter and $100 \mathrm{~mm}$ long. An obstacle was placed inside the venting duct, $73 \mathrm{~mm}$ away from the combustion vessel, which consisted of steel orifice plate with external diameter equal to the inner diameter of the venting duct and a central unobstructed hole, providing a fixed blockage ratio.

During testing, the open end of the venting duct was firstly covered by thin plastic membrane sealed by bolted flanges, giving an adequate range of vent failure pressures. The vessel was evacuated and then filled to atmospheric pressure with a combustible 
mixture, which was prepared from components by the partial pressure method and stored in a container over 24 hours. The mixture was ignited by an electrical spark produced by an igniter. Once the pressure inside the vessel, generated by combustion, exceeded the bursting pressure, the venting duct opened to atmosphere due to the membrane rupture, allowing hot gas to escape from the vessel.

Five piezoelectric transducers (Kistler 211B) were mounted at various venting locations respectively, in which one (P-1 in Fig. 1) was mounted at the wall of the venting exit and the others (P-2 5 in Fig. 1) were placed along the outside axis of the vessel with intervals of $100 \mathrm{~mm}$ starting a distance of $80 \mathrm{~mm}$ from the venting exit. Two more transducers $\left(\mathrm{P}_{\mathrm{i}}-1,2\right)$ were installed inside the vessel for recording the pressure history inside. The signals were transmitted to the signal coupler (Kistler 5124) and recorded on the 8-channal transient records (JV5200). Fig. 2 shows the pressure history at measuring point $\mathrm{P}_{\mathrm{i}}-1$ inside the vessel.

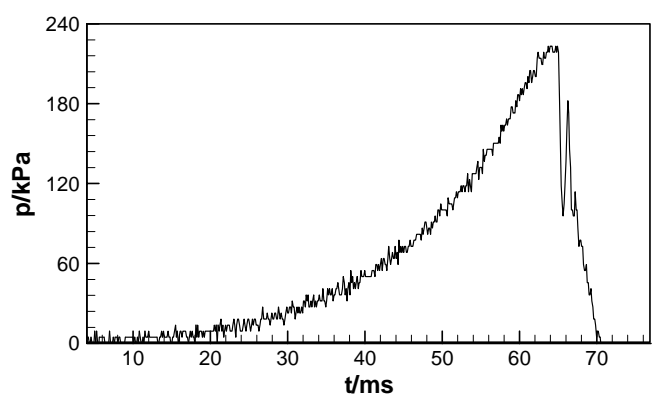

Fig. 2. Pressure-time profiles inside the vessel at $\mathrm{P}_{\mathrm{i}}-1$ in Test T3.

The patterns of the external flow field after vent were recorded by a high speed framing shadow photography, composed of a 16-spark light source, a concave mirror and a camera fitted with 16 arranged optical lenses, which can take a series of shadow pictures during each experimental. An interval between two sequential sparks is controlled by a time control system.

Ignition and start-up of data acquisition system were automatically sequenced when the control system and the spark light sources were trigged simultaneously by the pressure transducer P1. Schematics of experimental set-up and shadowgraph system were shown schematically in Fig. 3.

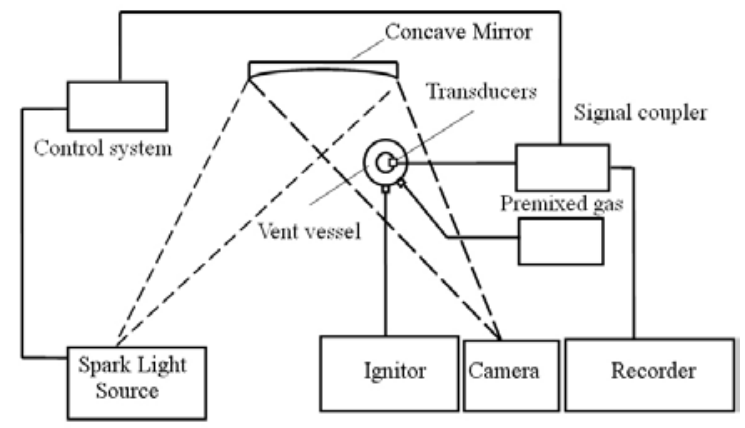

Fig. 3. Schematics of experimental set-up and shadowgraph system. 
A series of the explosion venting tests, listed in table 1, has been carried out, covering three equivalent ratios of methane-air mixture $(\varphi=0.7,1,1.3)$, three failure pressures $\left(p_{v}=140 \mathrm{kPa}, 230 \mathrm{kPa}, 350 \mathrm{kPa}\right)$ and three blockage ratios of obstacles $(\mathrm{BR}=0.0 \%, 17.8 \%$, $40.2 \%$, here BR means the percentage of the cross area obstructed by the obstacle to the whole section area of the duct).

Table 1. Vented explosion test conditions.

\begin{tabular}{l|c|c|r}
\hline \multicolumn{1}{c|}{ Test } & $\begin{array}{c}\text { Equivalent ratio } \\
\text { of } \mathbf{C H}_{4} \text {-Air }(\boldsymbol{\varphi})\end{array}$ & $\begin{array}{c}\text { Failure pressure } \\
\left(\boldsymbol{p}_{\boldsymbol{v}}\right)\end{array}$ & $\begin{array}{c}\text { Blockage ratio of } \\
\text { obstacle (BR) }\end{array}$ \\
\hline $\mathrm{ynnn} \mathrm{T} 1$ & 0.7 & $230 \pm 15 \mathrm{kPa}$ & $0.0 \%$ \\
\hline $\mathrm{T} 2$ & & $350 \pm 15 \mathrm{kPa}$ & $0.0 \%$ \\
\hline $\mathrm{T} 3$ & \multirow{3}{*}{1.0} & $230 \pm 15 \mathrm{kPa}$ & $0.0 \%$ \\
\cline { 4 - 4 } $\mathrm{T} 4$ & & $140 \pm 15 \mathrm{kPa}$ & $0.0 \%$ \\
\cline { 4 - 4 } $\mathrm{T} 5$ & & $230 \pm 15 \mathrm{kPa}$ & $17.8 \%$ \\
\cline { 4 - 4 } $\mathrm{T} 6$ & & $230 \pm 15 \mathrm{kPa}$ & $40.2 \%$ \\
\hline $\mathrm{T} 7$ & 1.3 & $230 \pm 15 \mathrm{kPa}$ & $0.0 \%$ \\
\hline
\end{tabular}

\section{NUMERICAL}

The flame propagation inside the vessel and its venting process (Test T3) was simulated by using SIMPLE schemes [9] based on $k-\varepsilon$ turbulent model and "Eddy Dissipation" combustion model [10]. The computational domain was shown in the Fig. 4. To be able to account for the large gradients of parameters near the boundaries(the vessel wall) in a coarse grid computation, the wall functions [11] were used, which were derived from the two dimensional turbulent boundary layer. The outer boundary in the external flow field was the open air system. It was assumed that $15 \%$ fuel (premixed gas) on the bottom end of the vessel, was consumed initially during ignition process and the failure pressure of the vent bursting disc was $230 \mathrm{kPa}$ (Test T3).

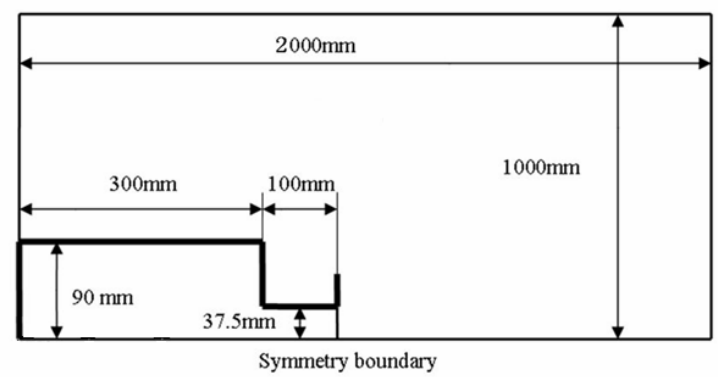

Fig. 4. Schematics of the computational domain.

\section{RESULTS AND DISCUSSION}

\section{External Explosion}

Corresponding to the test case T3 in table 1 , where the equivalent ratio of methane-air $\varphi=1$, the failure pressure $p_{v}=230 \pm 10 \mathrm{kPa}$ and the blockage ratio $\mathrm{BR}=0$, the time histories of pressures at different locations placed with the pressure transducers are shown in Fig. 5, where a) measured and b) calculated. From which it can be seen that 
there exist two pressure peaks in the external flow field. The first one, called the rupture shock, is generated by the membrane rupture and the second one with much higher pressure, called the external explosion wave, is generated by the violent combustion of the combustible gas expelled from the vessel in venting. The peak pressure-spatial location traces for these waves are given in Fig. 6, where a) measured and b) calculated. From Fig. 6a, the pressure of the rupture shock wave decreases from $18.8 \mathrm{kPa}(\mathrm{P}-2)$ to $8.4 \mathrm{kPa}(\mathrm{P}-5)$ and subsequently drops to an acoustic wave. But the pressure of the external explosion increases from $13.6 \mathrm{kPa}(\mathrm{P}-2)$ to $53.6 \mathrm{kPa}(\mathrm{P}-4)$ and then drops to $37.7 \mathrm{kPa}(\mathrm{P}-5)$. The same tendencies are also demonstrated from the calculated results in Fig. 6b.
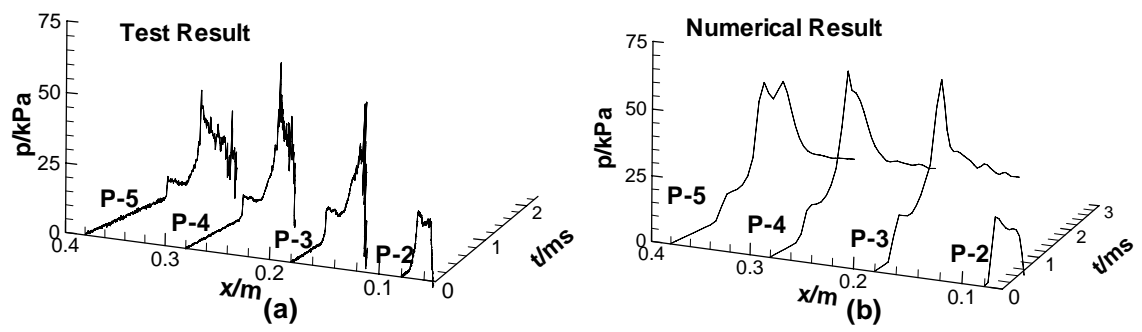

Fig. 5. The pressure time histories (a) measured (b) calculated.

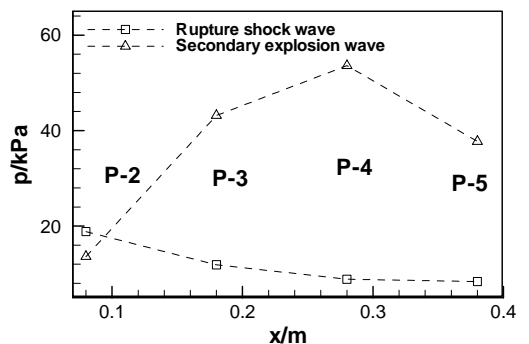

(a)

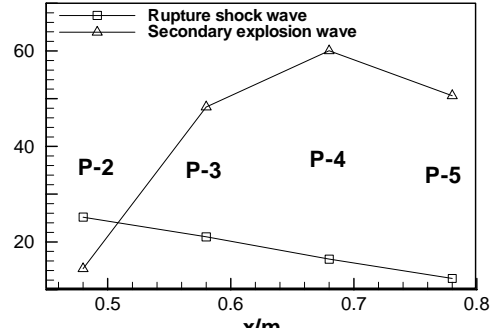

(b)

Fig. 6. Peak pressure-distance traces of rupture shock wave and secondary explosion wave (a) measured, (b) calculated.

\section{Dynamic Processes of External Explosion}

A detailed description of the dynamic processes in the external flow field is helpful to understand the dominant mechanism of the occurrence of the external explosion during venting. It is discussed as follows based on numerical and experimental studies.

When a precursor rupture shock wave discharges from the venting duct after membrane breaking, a turbulent unburned mixture expands out of the duct as a jet flow behind the shock wave and then forms a combustible cloud in the external flow field. A negative pressure phase is induced by Prandtl-Meyer expansion on the venting exit. But in front of it, there exists a high pressure region due to the barrel shock wave and its Mach disc induced by focused waves reflected from the cloud boundary. Assuming that the expelled gas is not ignited in calculations, the calculated pressure distributions in the external flow field at various sequential times during the venting are shown in Fig. 7. It can be seen that the pressure behind the rupture shock wave decreases rapidly, meanwhile the pressure behind the Mach disc increases at the beginning and decreases finally. 
When the released gas is ignited in the external flow field, the flame accelerates continuously as it enters into the duct due to the flame-turbulent interaction induced by the tube wall. After passing through the venting duct, a flame jet emerges into the cloud with high velocity, as shown in Fig. 8, plotted by calculated results, where the region between the vertical dash lines represents the venting duct.

The flame jet might cause the cloud to burn up and results in the external explosion if the gas density in the cloud and the pressure behind the Mach disc are enough high.

A sequence of shadow photographs of the external flow field taken from experiments and calculations is shown in Fig. 9, where time $t$ is taken zero at the membrane breaking. Rayleigh-Taylor and Helmholtz instabilities on the flame surface are triggered due to the different densities and velocities between the burned and unburned gases. The highly turbulent flame front appeared clearly in the figures spreads rapidly with a mushroomlike shape. Under the action of the continuously accelerating flame, a series of compressive waves is observed considerably. Especially, when the combustible gas in the high pressure region behind Mach disc is ignited, a vigorous burn-up will increase the severity of the overpressure, the shock fronts of the external explosion can be seen in Fig. 9c and d.
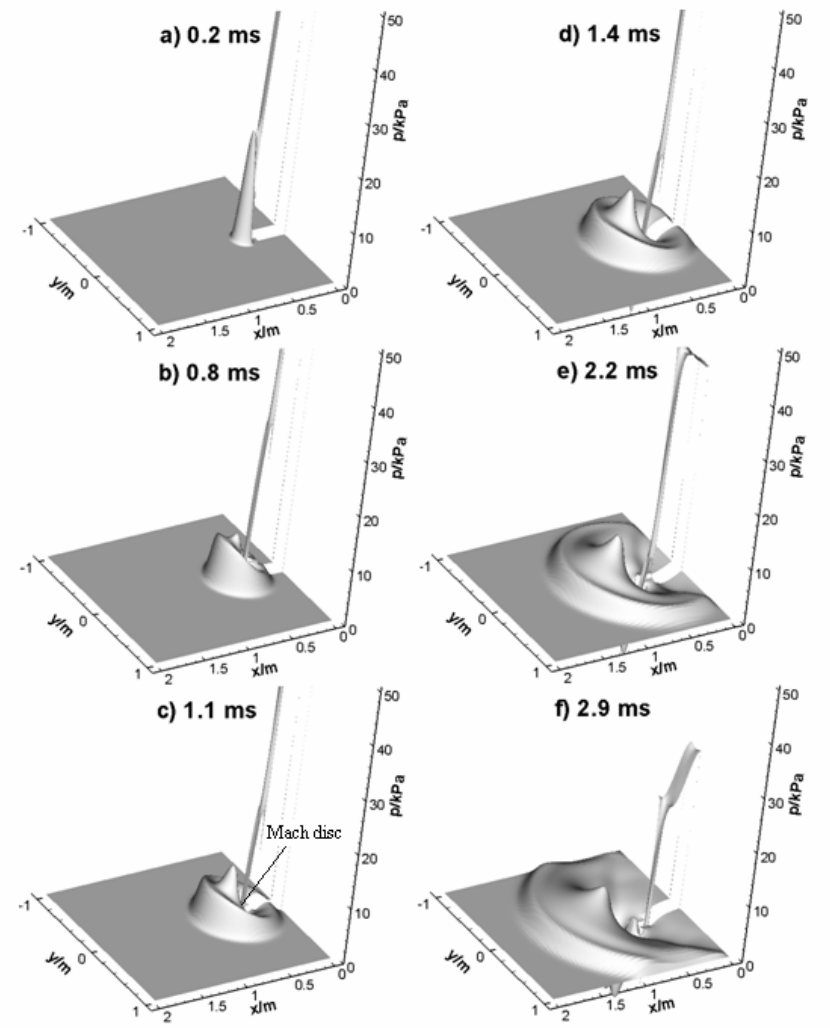

Fig. 7. Calculated pressure distributions in the external flow field during venting (released gas not ignited). 


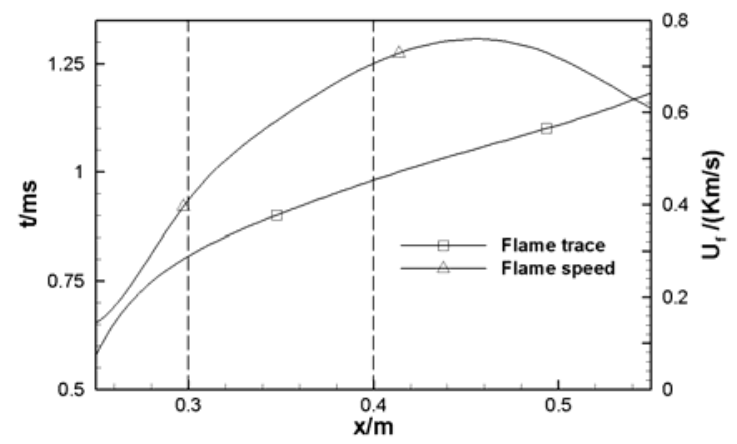

Fig. 8. Trace and speed of the flame along the axis.

In order to describe the formation and evolution of external explosions during the venting further, the predicted distributions of external pressures in a symmetry plane at various sequential time stages are depicted in Fig. 10, where peak pressures propagated divergently with a roughly spherical shape about the vessel axis. In the early stage of venting, only the rupture shock wave is observed as shown in Fig. 10a and then decreases gradually with increasing time as shown in Fig. 10b-f. An under-expansion of unburned gas expelled from the vessel results in the generation of the Mach disc with quasi-static secondary peak pressures in a distance apart from the exit of the vent duct near axis region shown in Fig. 10b. While the combustible gas in the Mach disc region is ignited by the flame jet ejected from the vessel and burned rapidly, the secondary peak pressure rises dramatically, leading to the external explosion as shown in Fig. 10b-d. The external explosion wave propagates expansively and decreases with the exhaustion of combustible gas, shown in Fig. 10e-f.
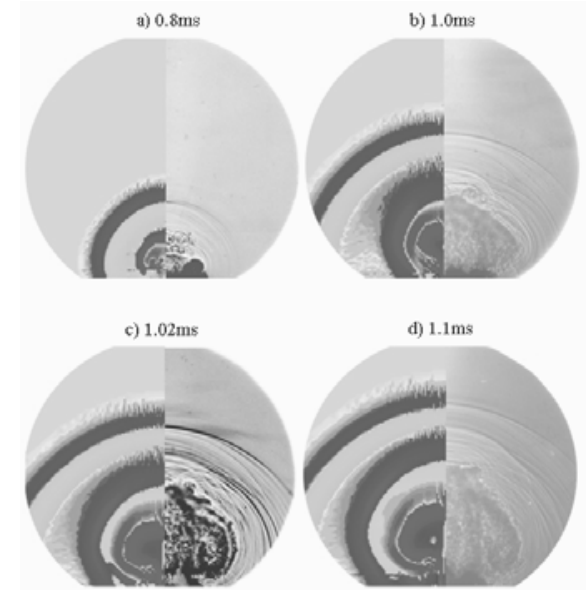

Fig. 9. Calculated (the left half) and measured (the right half) shadowgraphs of the external flow field during venting. 

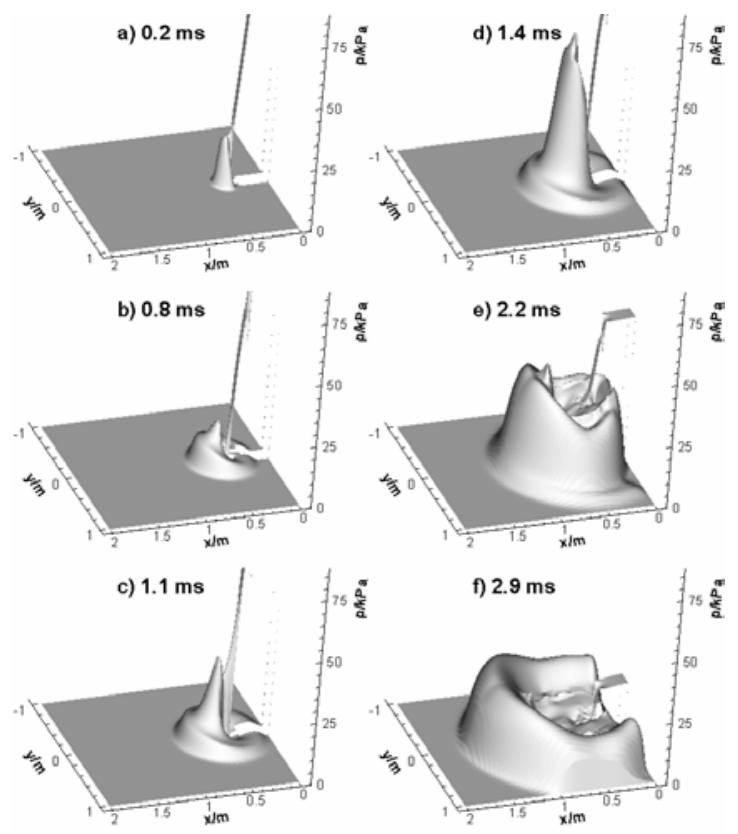

Fig. 10. Predicted pressure distributions in external flow field during the venting.

\section{Effects on External Explosions}

The external explosions depended closely on the flow patterns of expelled gas cloud are strongly affected by many factors, such as size and shape of the vessel, venting area, failure pressure and fuel type etc.

The experiments with different failure pressures $p_{v}=350 \mathrm{kPa}, 230 \mathrm{kPa}$ and $140 \mathrm{kPa}$, i.e., the test cases T2, T3 and T4 in table1, have been conducted. Its results are shown in Fig. 11, where a) the peak pressure-spatial location traces and b) the variations of the maximum pressure (intensity of the external explosion) occurred outside the vessel in the venting processes with the failure pressures.
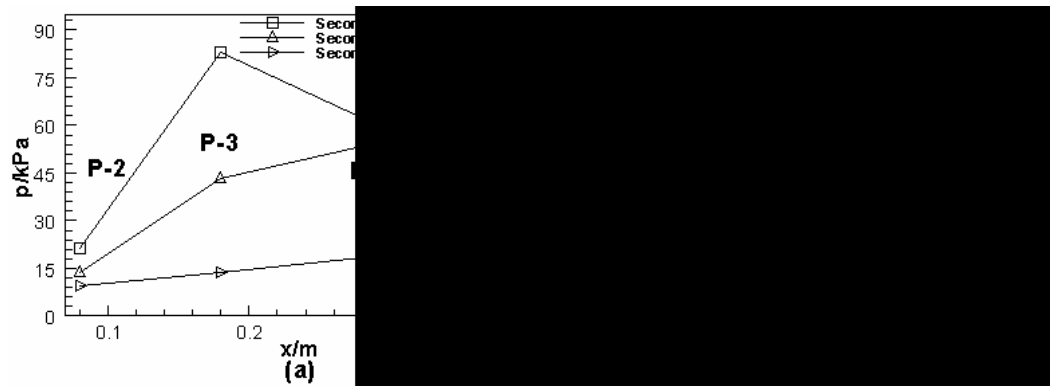

Fig. 11. Peak pressure-distance traces of external explosion wave for different failure pressure (a) and Variations of external maximum pressure with failure pressure (b).

The vented combustible cloud is denser and ignited in the shorter run after venting, hence, the maximum pressure is higher and the location of its occurrence is closer to the duct exit for a higher failure pressure than that for a lower one. But since the more fuel is 
consumed in the vessel prior to the venting for the high failure pressure, the peak pressure in external flow field decays quickly. For a much lower failure pressure, e.g., the test case $\mathrm{T} 4$ of $p_{v}=140 \mathrm{kPa}$, the combustible vented gas has been previously diluted by ambient air before the flame jet comes out, so that the external explosion is not apparent in Fig. 11.

The experiments have been performed with different blockage ratios of obstacle $\mathrm{BR}=0.0 \%$ (T3), $17.8 \%$ (T5) and $40.2 \%$ (T6), to discuss the effects of the obstacles on the external pressure, which are presented in Fig. 12. It can be seen that the maximum pressure outside the vessel in venting processes decreases with BR increasing, which can be explained as that the size and reactivity of the vented unburned cloud is smaller as ignited for a large BR than that for small BR.

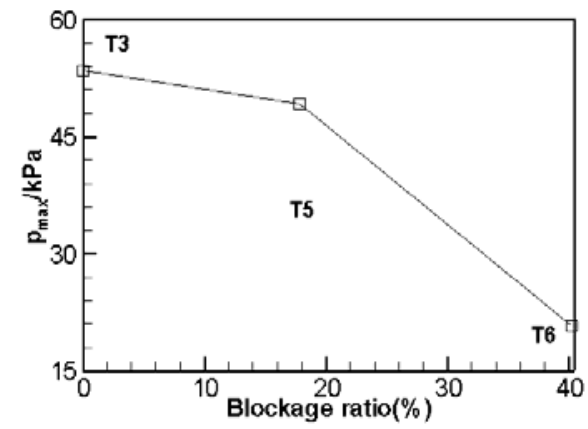

Fig. 12. Variation of the external maximum pressure with BR.

The variations of the intensity of the external explosion during venting with the equivalent ratio are shown in Fig. 13 based on experimental results with equivalent ratios $\varphi=0.7$ (T1), 1.0 (T3) and 1.3 (T7). The equivalent ratio of the mixture gas will decrease when the unburned gas is expelled into air and mixed with it, which increases the fuel consumption when its initial equivalent ratio lightly exceeded the chemical equivalent. Therefore, the external maximum pressure decreases with the equivalent ratio decreasing as shown in Fig. 13.

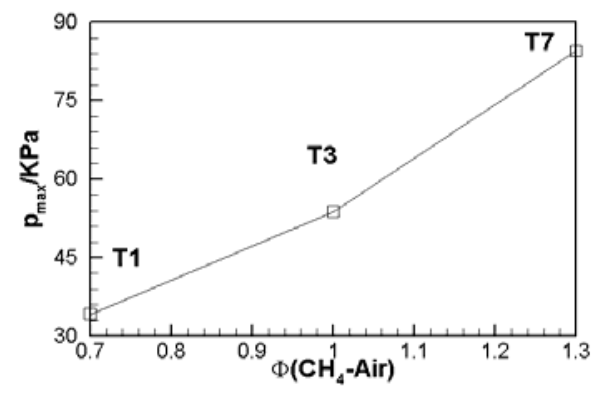

Fig. 13. Variation of the external maximum pressure with equivalent ratio.

\section{CONCLUSIONS}

Based on the experimental and theoretical study on external explosions in venting, the dynamic processes of the formation of external explosions are described in detail. Prior to ignition, the turbulent unburned mixture cloud is generated behind the rupture shock wave during the venting. Within it there exists a high pressure region induced by the 
barrel shock wave and its Mach disc due to the under-expansion of unburned gas. Then, a flame jet penetrates into the cloud and spreads with a mushroom-like shape. The pressure might increase rapidly during the burning of the combustible mixture behind Mach disc before dramatically decaying, which results in external explosions. The external explosion closely dependents on the flame jet velocity and the flow pattern of expelled gas cloud and strongly affected by many factors.

\section{REFERENCES}

[1] Cooper, M.G., Fairweather, M., and Tite J.P., "On the Mechanisms of Pressure Generation in Vented Explosions,” Combustion and Flame, 65:1-14 (1986).

[2] Ponizy, B. and Leyer, J.C., "Flame Dynamics in a Vented Vessel Connected to a Duct: 1. Mchanism of Vessel-Duct Interaction," Combustion and Flame, 116:259-271 (1999).

[3] Ponizy, B. and Leyer, J.C., "Flame Dynamics in a Vented Vessel Connected to a Duct: 2. Influence of Ignition Site, Membrane Rupture, and Turbulence," Combustion and Flame, 116:272-281 (1999).

[4] Hu, J., Pu, Y.K., Wan, S.X., and Jia, F., "Experimental Investigations of Pressure Development During Explosion Vent from Cylindrical Vessels," Explosion and Shock Waves, 21(1):48-52 (2001).

[5] Razus, D.M. and Krause, U., "Comparison of Empirical and Semi-Empirical Calculation Methods for Venting of Gas Explosions," Fire Safety Journal, 36:123 (2001).

[6] Forcier, T. and Zalosh, R., "External Pressures Generated by Vented Gas and Dust Explosions," Journal of Loss Prevention in the Process Industries, 13:411417 (2000).

[7] Harrison, A.J. and Eyre, A.J., “' 'External Explosions’ as a Result of Explosion Venting,” Combustion Science and Technology, 52:91-106 (1987).

[8] Catlin, C.A., "Scale Effects on the External Combustion Caused by Venting of a Confined Explosion,” Combustion and Flame, 83:399-411 (1991).

[9] Majumdar, S., "Role of Underrelaxation in Momentum Interpolation for Calculation of Flow with Nonstaggered Grids," Numer Heat Transfer, 15:125132 (1988).

[10] Hjertager, B.H., "Simulation of Transient Compressible Turbulent Reactive Flows,” Combustion Science and Technology, 27:159-170 (1982).

[11] Launder, B.E. and Spalding, D.B., "The Numerical Computation of Turbulent Flows," Computer Methods in Applied Mechanics and Engineering, 3:269-289 (1974). 